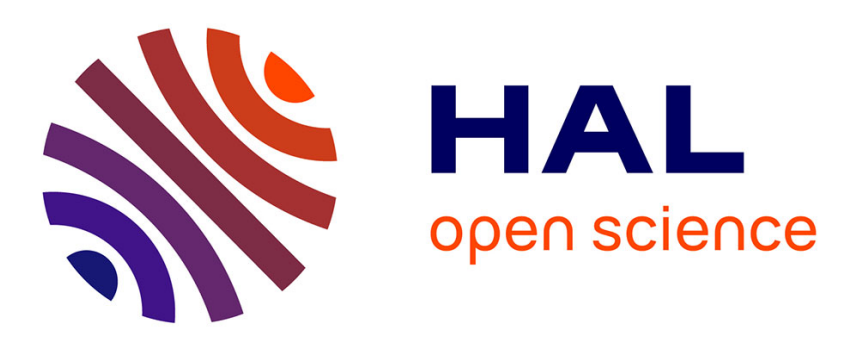

\title{
A National Healthcare Response to Intensive Care Bed Requirements during the COVID-19 Outbreak in France
} Jean-Yves Lefrant, Marc-Olivier Fischer, Hugo Potier, Cécile Degryse, Samir Jaber, Laurent Muller, Julien Pottecher, Hélène Charboneau, Eric Meaudre, Pierre Lanot, et al.

\section{To cite this version:}

Jean-Yves Lefrant, Marc-Olivier Fischer, Hugo Potier, Cécile Degryse, Samir Jaber, et al.. A National Healthcare Response to Intensive Care Bed Requirements during the COVID-19 Outbreak in France. Anaesthesia Critical Care \& Pain Medicine, 2020, 10.1016/j.accpm.2020.09.007 . hal-02962780

\section{HAL Id: hal-02962780 \\ https://hal.science/hal-02962780}

Submitted on 2 Nov 2020

HAL is a multi-disciplinary open access archive for the deposit and dissemination of scientific research documents, whether they are published or not. The documents may come from teaching and research institutions in France or abroad, or from public or private research centers.
L'archive ouverte pluridisciplinaire HAL, est destinée au dépôt et à la diffusion de documents scientifiques de niveau recherche, publiés ou non, émanant des établissements d'enseignement et de recherche français ou étrangers, des laboratoires publics ou privés. 


\title{
A national healthcare response to intensive care bed requirements during the COVID-19 outbreak in France
}

\author{
Jean-Yves Lefrant ${ }^{\mathrm{a}, *}$, Marc-Olivier Fischer ${ }^{\mathrm{b}}$, Hugo Potier ${ }^{\mathrm{c}}$, Cécile Degryse ${ }^{\mathrm{d}}$, Samir Jaber ${ }^{\mathrm{e}}$, \\ Laurent Muller ${ }^{\mathrm{a}}$, Julien Pottecher ${ }^{\mathrm{f}}$, Hélène Charboneau ${ }^{\mathrm{g}}$, Eric Meaudre ${ }^{\mathrm{h}}$, Pierre Lanot ${ }^{\mathrm{i}}$, \\ Vincent Bruckert ${ }^{\mathrm{j}}$, Benoît Plaud ${ }^{\mathrm{k}}$, Bertrand Dureuil ${ }^{1}$, Emmanuel Samain ${ }^{\mathrm{m}}$, Hervé Bouaziz ${ }^{\mathrm{n}}$, \\ Claude Ecoffey ${ }^{\mathrm{o}}$, Xavier Capdevila ${ }^{\mathrm{p}}$, for the French ICU study investigators group ${ }^{1}$
}

${ }^{a}$ EA 2992 IMAGINE, Univ Montpellier, Pôle Anesthésie Réanimation Douleur Urgence, CHU Nîmes, Nîmes, France

b Normandie Univ, UNICAEN, CHU de Caen Normandie, Service d'Anesthésie Réanimation, 14000 Caen, France

${ }^{\mathrm{c}}$ Laboratoire de Biostatistique, Epidémiologie clinique, Santé Publique Innovation et Méthodologie (BESPIM), Pôle Pharmacie, Santé publique, CHU Nîmes,

Nîmes, University of Montpellier, France

${ }^{\mathrm{d}}$ Service d'Anesthésie Réanimation Pellegrin Tripode, CHU Bordeaux, Bordeaux, France

e Department of Anaesthesia E Critical Care Medicine, University of Montpellier Saint Eloi Hospital, and PhyMedExp, University of Montpellier, INSERM, CNRS, Montpellier, France

${ }^{\mathrm{f}}$ Hôpitaux Universitaires de Strasbourg, Pôle d’Anesthésie-Réanimation \& Médecine Péri-Opératoire, Service d'Anesthésie-Réanimation E̛ Médecine PériOpératoire Hôpital de Hautepierre - Université de Strasbourg, Faculté de Médecine, Fédération de Médecine Translationnelle de Strasbourg (FMTS), UR3072, Strasbourg, France

${ }^{\mathrm{g}}$ Service d'Anesthésie, Clinique Pasteur, 31300 Toulouse, France

${ }^{\mathrm{h}}$ Fédération d'Anesthésie-Réanimation, Hôpital d'Instruction des Armées Sainte-Anne, Toulon; Chaire d'Anesthésie-réanimation, Médecine d'Urgence, École du Val-de-Grâce, Paris, France

'GARHPA, groupe de anesthésistes réanimateurs de l'Hôpital Privé d'Antony, 92160 Antony, France

${ }^{j}$ Pôle d'Anesthésie-Réanimation Médecine péri-opératoire et Urgences, Hôpital l'Archet 2, Centre Hospitalier Universitaire de Nice, Université de Nice, 06000 Nice, France

${ }^{\mathrm{k}}$ Paris University \& APHP. Nord. DMU PARABOL, Department of Anaesthesiology, Critical Care \& Burn Unit, Saint-Louis hospital, 1, Avenue Claude Vellefaux, 75010 Paris, France

${ }^{1}$ Departement of Anaesthesia and Critical Care, Rouen University Hospital, Rouen, France

${ }^{\mathrm{m}}$ Département d'Anesthésie Réanimation, Hôpital Jean Minjoz - C.H.U. de Besançon, Besançon, France

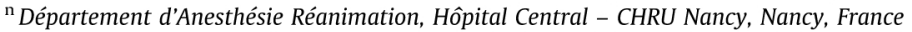

o Département d'Anesthésie-Réanimation et Médecine Péri-Opératoire, Hôpital Pontchaillou, Université Rennes 1, Rennes, France

${ }^{\mathrm{P}}$ Department of Anaesthesiology and Critical Care Medicine, Lapeyronie University Hospital and Montpellier University. INSERM unit 1051, Montpellier

Neurosciences Institute, Montpellier, France

\footnotetext{
* Corresponding author.

E-mail address: jean.yves.lefrant@chu-nimes.fr (J.-Y. Lefrant).

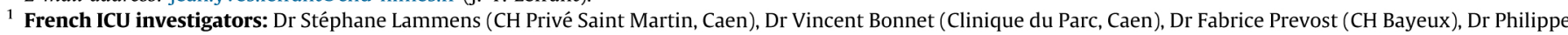

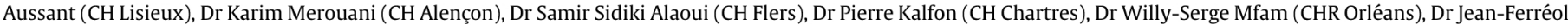

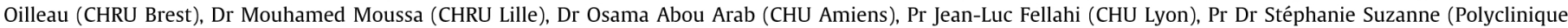

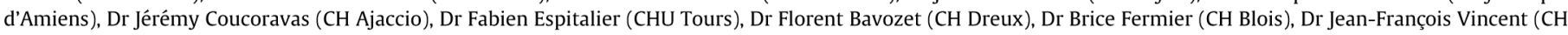

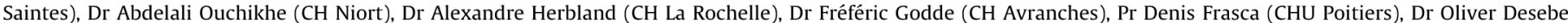

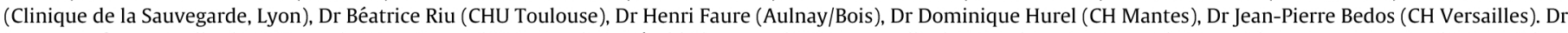

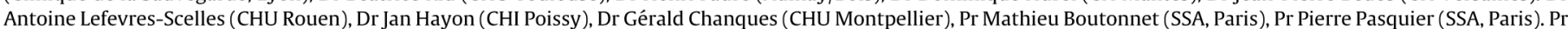

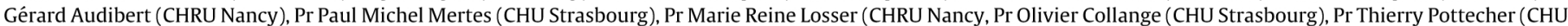

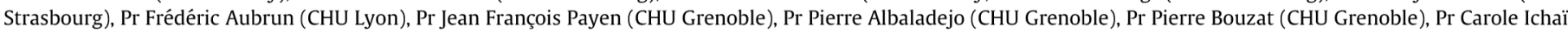

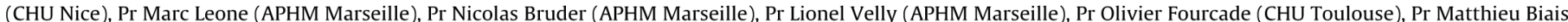

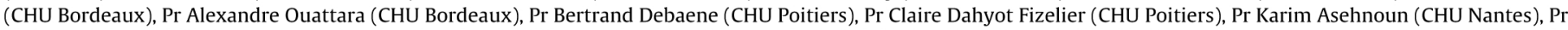

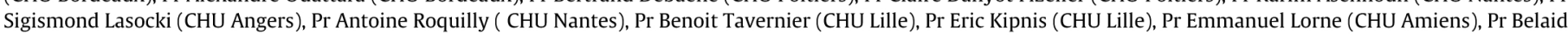

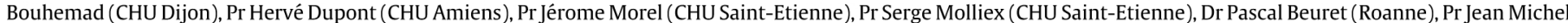

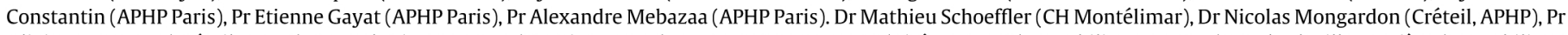

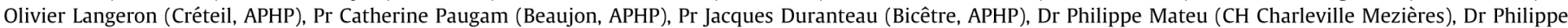
Verdier (CH Montluçon), Dr Clément Buléon (CHU Caen).
} 
Keywords:

COVID-19

France

ICU

Bed availability
Background: Whereas 5415 Intensive Care Unit (ICU) beds were initially available, 7148 COVID-19 patients were hospitalised in the ICU at the peak of the outbreak. The present study reports how the French Health Care system created temporary ICU beds to avoid being overwhelmed.

Methods: All French ICUs were contacted for answering a questionnaire focusing on the available beds and health care providers before and during the outbreak.

Results: Among 336 institutions with ICUs before the outbreak, 315 (94\%) participated, covering 5054/ 5531 (91\%) ICU beds. During the outbreak, 4806 new ICU beds (+95\% increase) were created from Acute Care Unit (ACU, 2283), Post Anaesthetic Care Unit and Operating Theatre (PACU \& OT, 1522), other units (374) or real build-up of new ICU beds (627), respectively. At the peak of the outbreak, 9860, 1982 and 3089 ICU, ACU and PACU beds were made available.

Before the outbreak, 3548 physicians (2224 critical care anaesthesiologists, 898 intensivists and 275 from other specialties, 151 paediatrics), 1785 residents, 11,023 nurses and 6763 nursing auxiliaries worked in established ICUs. During the outbreak, 2524 physicians, 715 residents, 7722 nurses and 3043 nursing auxiliaries supplemented the usual staff in all ICUs. A total number of 3212 new ventilators were added to the 5997 initially available in ICU.

Conclusion: During the COVID-19 outbreak, the French Health Care system created 4806 ICU beds (+95\% increase from baseline), essentially by transforming beds from ACUs and PACUs. Collaboration between intensivists, critical care anaesthesiologists, emergency physicians as well as the mobilisation of nursing staff were primordial in this context.

\section{Introduction}

The COVID-19 caused a worldwide outbreak of respiratory illnesses that quickly invaded the world [1,2]. Its most severe form causes an acute respiratory distress syndrome (ARDS) requiring mechanical ventilation and thus Intensive Care Unit (ICU) admission. The World Health Organization recommendations tried to prevent cross-contamination in order to flatten the curve of the disease, reduce morbidity and mortality and prevent situations in which the capacity of various healthcare systems would be exceeded [3].

After China, COVID-19 quickly spread to Europe, first to Italy, then Spain and France. In France, the first cases were diagnosed on the $24^{\text {th }}$ of January 2020 and the outbreak quickly spread throughout the north-eastern part of the country, rapidly overwhelming their ICU capacity [4]. For the first time, the French government decided to apply the national plan for healthcare institutions (named "Plan Blanc"), postponing all scheduled nonurgent surgical and medical procedures. A complete nation-wide lockdown was also decided on the $17^{\text {th }}$ of March 2020 [5].

To prevent ICUs from being overwhelmed, national and regional healthcare institutions (the French Health Ministry and all Regional Health Agencies) decided to increase the availability of ICU beds by creating new temporary ICU beds in institutions that may or may not have had an ICU prior to the outbreak. The availability of ICU beds was assessed daily in each institution and at the regional level to organise, if necessary, potential patient transfers between regional and national hospitals [6-8]. The unprecedented overall mobilisation and joint efforts of various medical, paramedical and administrative staffs enabled caregivers to manage the most serious cases in each ICU [9]. Following the example of Bergamo hospital in Italy, all physicians who could manage ICU patients were involved in dealing with the crisis $[10,11]$. French anaesthesiologists (with a minimum of two years' ICU training during their curriculum) were also involved, since surgical activities were reduced to emergencies and procedures difficult to postpone (such as cancer) $[6,11]$. On the $8^{\text {th }}$ of April, thanks to this overall organisation, 7148 patients were hospitalised in ICU beds, whereas the official national capacity before COVID-19 outbreak was only 5432 ICU beds [12,13].

The present study therefore describes how new ICU beds were created in France to receive the first wave of the most severely ill COVID-19 patients and what type of healthcare professionals were mobilised to care for these patients.

\section{Methods}

This retrospective multicentric observational study was approved by the Institutional Review Board of the French Society of Anaesthesia and Intensive Care (CERAR\# 00010254-2020-094, $6^{\text {th }}$ of May 2020) and registered on Clinical Trials (NCT04420286) [14]. STROBE recommendations for observational studies were followed [15].

\subsection{Management of ICU patients in France [16]}

Three types of units for managing the most seriously ill patients can be distinguished: i) Intensive Care Units (ICU) are dedicated to patients with (or at risk of) at least two organ failures; ii) Continuous Care Units (CCU) for patients with only one organ failure specific to a particular medical specialty (cardiology, neurology, nephrology...); iii) Acute Care Units (ACU) dedicated to patients at risk of developing an organ failure in postoperative or medical settings. In December 2018, the number of available ICU beds was 5432 among 325 healthcare facilities (ICU beds from military hospitals and hospitals in overseas territories (Polynésie Française and Nouvelle Calédonie) were not included in this evaluation) [13].

Physicians working in ICUs may be primarily trained in anaesthesiology or intensive care medicine. Any anaesthesiologist can work in an ICU as a "critical care anaesthesiologist" or in procedural area as anaesthesiologist. These two professions are interchangeable throughout their career.

There is no mandatory bed-to-physician ratio but during the day, about 4 full-time physicians are required for 10 ICU beds and 2 for 10 ACU beds [16]. For nurses, a ratio of 2 ICU nurses for 5 patients and 1 nursing auxiliary for 4 patients is a legal requirement in the ICU. 


\subsection{Participants}

From the $2^{\text {nd }}$ of May to the $12^{\text {th }}$ of June 2020, all French ICU managers (both physicians and nurses) were contacted by e-mail or phone to participate in the study. Agreement to respond was considered as consent to participate.

Inclusion criteria: All French medical institutions for which the Head Manager agreed to respond to the survey by e-mail or phone.

Non-inclusion criteria: French medical institutions which had declined to participate or could not be contacted.

\subsection{Questionnaire and parameters measured: (Supplementary material)}

The questionnaire was available via a web link. There was one link per department (95 metropolitan departments, one per overseas department and territories and three for military institutions (permanent military hospitals, transient military hospital and transfer team). The questionnaire was in four different sections and took 15-25 min to be completed.

Section 1 focused on the organisation before the COVID-19 outbreak (defined before the $1^{\text {st }}$ of February): number of ICU, ACU and Post-Anaesthetic Care Unit (PACU) (or recovery room) beds in the institution, number of intensivists and critical care anaesthesiologists, residents and fellows, nurses and nursing auxiliaries in the unit.

Section 2 included the date of creation of different types of beds. New temporary ICU beds could be issued from the transformation of ACU, PACU or operating theatres (OT) or any medical or surgical ward at the institution or from the construction of new ICU wards during the COVID-19 outbreak. Likewise, the number of ACU beds created from PACU or OT, other units or newly constructed was recorded. We also recorded the number of beds transformed from specialised surgical ICUs to classical ICUs (not considered as newly created ICU beds).

Section 3 focused on the number of new staff members (physicians, nurses and nursing auxiliaries) allocated to the ICU during the COVID-19 outbreak. The new dedicated intensivists, anaesthesiologists (used to working in OT), residents, fellows, nurses, operating theatre nurses, anaesthetic nurses and nursing auxiliaries involved in daily management were recorded.

The number of new ventilators used at these ICUs was also recorded in this section.

\subsection{Objectives}

The primary objective was to describe the number of new temporary ICU beds and their origin (ACU, PACU or OT, other unit, real creation) during the COVID-19 outbreak in France.

The secondary objective was to describe the human resources mobilised to cope with the surge in acute care patients.

\subsection{Statistical analysis}

Data were processed using the open-source REDCap Data Management Platform hosted by Nîmes University Hospital [17]. Quantitative variables are expressed in medians and ranges. Qualitative data are expressed in absolute numbers with percentages. As this was a strict observational study, no comparison was performed.

\section{Results}

\subsection{Bed capacity for ICU COVID-19 patients}

From 336 institutions with an ICU (5531 ICU beds) before the outbreak, 315 participated (response rate: 94\%), representing 5054 ICU beds (91\%) (Fig. 1). In these institutions, there were 3339 ACU and 4920 PACU beds (Fig. 2).

During the outbreak 4806 new ICU beds (+95\% increase) were created. Among them, 399 ICU beds were created in 43 institutions newly authorised to have an ICU. Fig. 2 displays the timing of this increase according to the origins of 4806 new ICU beds (3.805 (79\%) from ACUs (2283) and PACUs (1522)). At the peak of the outbreak, on the $8^{\text {th }}$ of April, $9860(+95 \%), 1982(-41 \%)$ and $3089(-37 \%)$ ICU, ACU and PACU beds were available, respectively, representing a total of 14,931 (+12\%) beds available for the most severely ill patients.

3.2. Availability of new human resources at ICUs, ACUs and PACUs during the COVID-19 outbreak (Fig. 3)

At baseline, 3548 physicians (2224 critical care anaesthesiologists, 898 intensivists and 275 from other specialties, 151 paediatricians), 1785 residents, 11,023 nurses and 6763 nursing auxiliaries were working in ICUs. During the outbreak, 2524 physicians, 715 residents, 7722 nurses and 3043 nursing auxiliaries

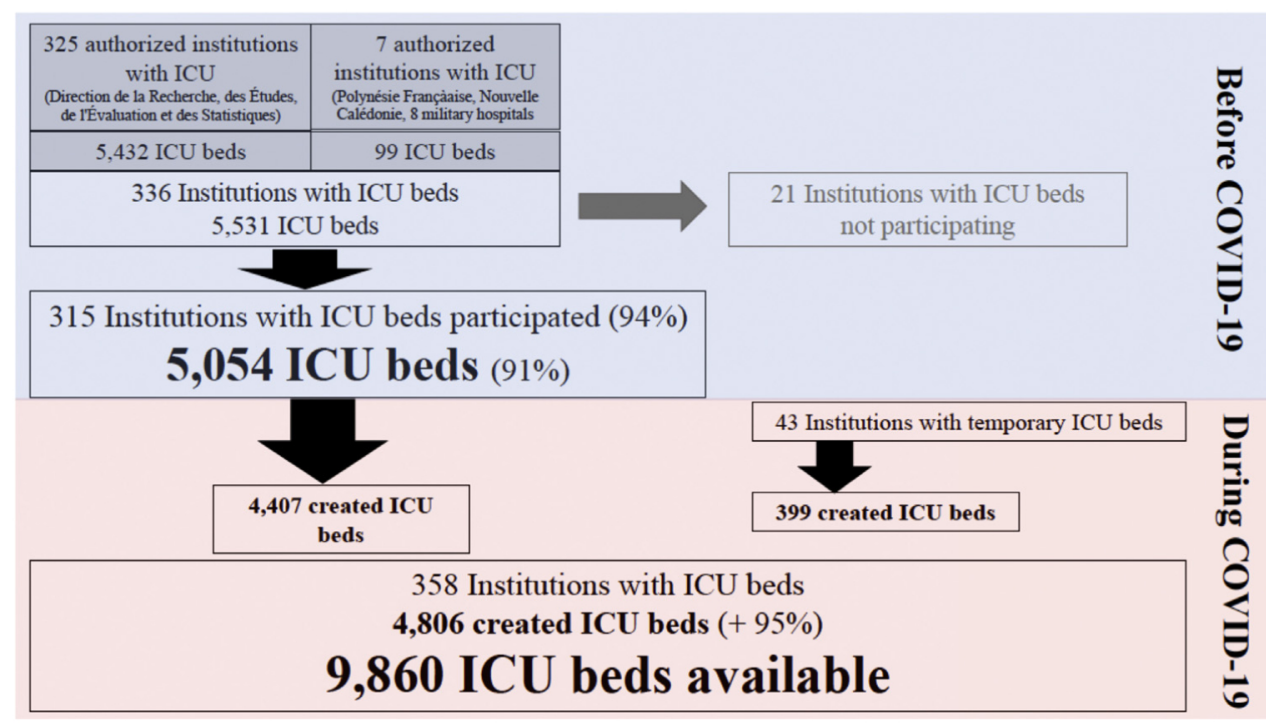

Fig. 1. Flow chart. ICU: Intensive Care Unit. 


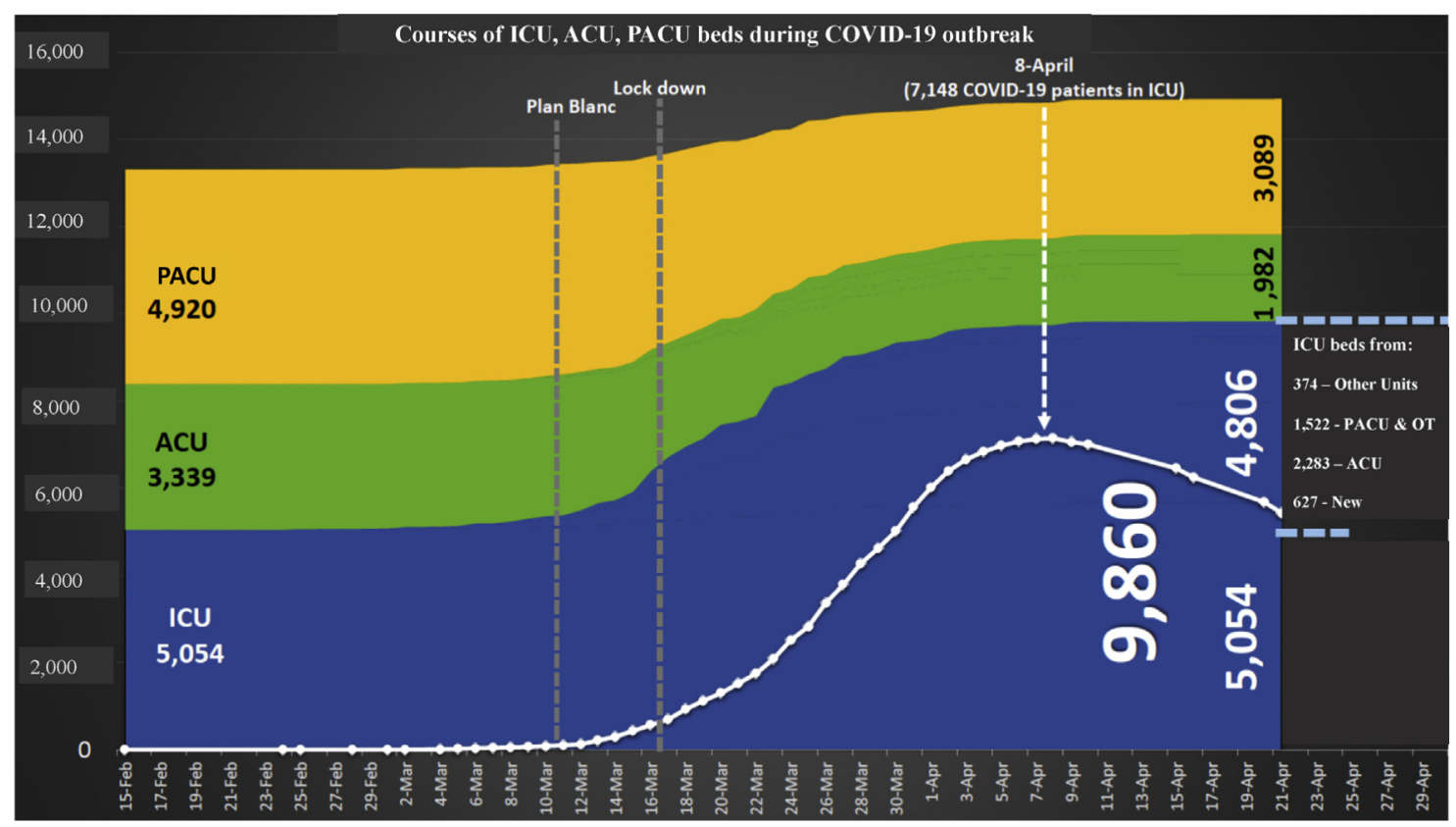

Fig. 2. Increase in ICU beds according to their origin. ICU: Intensive Care Unit. ACU: Acute Care Unit. PACU: Post Anaesthetic Care Unit. OT: Operating Theatre.

supplemented the usual staff to help manage patients in all the ICU beds.

\subsection{Ventilator availability}

From 5997 ventilators initially available, 3212 new ones (344, 399, 1423 and 1046 from Regional Health Agency, newly bought, PACUs/OTs and other units, respectively) were deployed, representing a total of 9209 ventilators.

\section{Discussion}

Based on the answers obtained from 315/336 institutions (94\%) with ICU, our study shows that these facilities were able to increase their ICU capacity from 5054 ICU beds available before outbreak to a total of 9860 beds at the peak of the outbreak. The French Health Care System was able to create 4806 additional temporary ICU beds by upgrading ACU $(n=2283)$, PACU, OT $(n=1522)$, and other units ( $n=374$ ) beds and creating completely new beds ( $n=627$ ). This increase in ICU beds enabled hospitals to cope with the peak of 7148 COVID-19 ICU patients on the $8^{\text {th }}$ of April. Due to the postponing of all elective procedures, health care providers with ICU training could be redeployed to help with patient management in these temporary ICUs ( 2524 physicians, 715 residents, 7722 nurses, 3043 nursing auxiliaries). A total of 3212 new ventilators were made available for the newly created ICU beds. However, this general increase was uneven, and some regions still had to transfer 644 patients to ICUs in other regions (in France or in the nearest foreign countries).

Over the last two decades, the risk of overwhelming of the ICU capacity was mainly described during terror attacks such as the New-York, Madrid, London, Paris and Nice attacks [18-22]. Such events required a prompt evaluation of bed availability for the most severely injured patients. Regarding human resources, all available caregivers were called in to readily support the in-house staff. The collaboration between emergency physicians, critical care anaesthesiologists, anaesthesiologists, intensivists, surgeons and radiologists was crucial to optimise patient care. Paris and Nice attacks occurred at night and the presence of non-used hospital beds at that time of the day greatly facilitated patient management $[21,22]$. In contrast to terror attacks, the COVID-19 pandemic has generated unprecedented requirements in additional ICU beds for more than two months. Hence, during the COVID-19 outbreak, the intent of postponing all elective procedures and of activating the national surge plan "Plan Blanc" was to obtain a long-lasting increase of the total number of hospital beds available.

During the COVID-19 outbreak, few studies have reported on how the various healthcare systems adapted. Bergamo hospital reported that new beds (adult, paediatric, surgical) had to be made quickly available together with the creation of short educational programs for non-critical care trained caregivers [10]. At New York's Presbyterian Weill Cornell Medical Center, ICU beds were created from beds available in OTs and PACUs that were not being used, as all elective procedures were cancelled [23]. In Boston, Massachusetts General Hospital transformed a 14-bed paediatric ICU into an adult ICU for one month so that 25 patients could be admitted, most of whom suffered from COVID-19 [24]. However, all these adaptations were achieved at a single centre representing 90 patients maximum. The present study is the first to report the response to the pandemic at the level of a national healthcare system. To date, only simulations and recommendations have been published [25,26].

The collaboration at all levels of the French healthcare system was crucial. At institutional level, the postponement of all elective procedures helped reallocate medical and paramedical personnel to staff all the units involved in the care of the most severely ill COVID-19 and non-COVID-19 patients. In the second half of March, some paediatric beds from specialised surgical ICUs, ACUs and PACUs were quickly transformed, leading to a 95\% increase in ICU bed capacity. In this context, after a dedicated training program, all non-used staff could be involved in ICU patient care, and anaesthesiologists with ICU training and anaesthetic nurses were first recruited to help manage these temporary ICU beds. 
Physicians
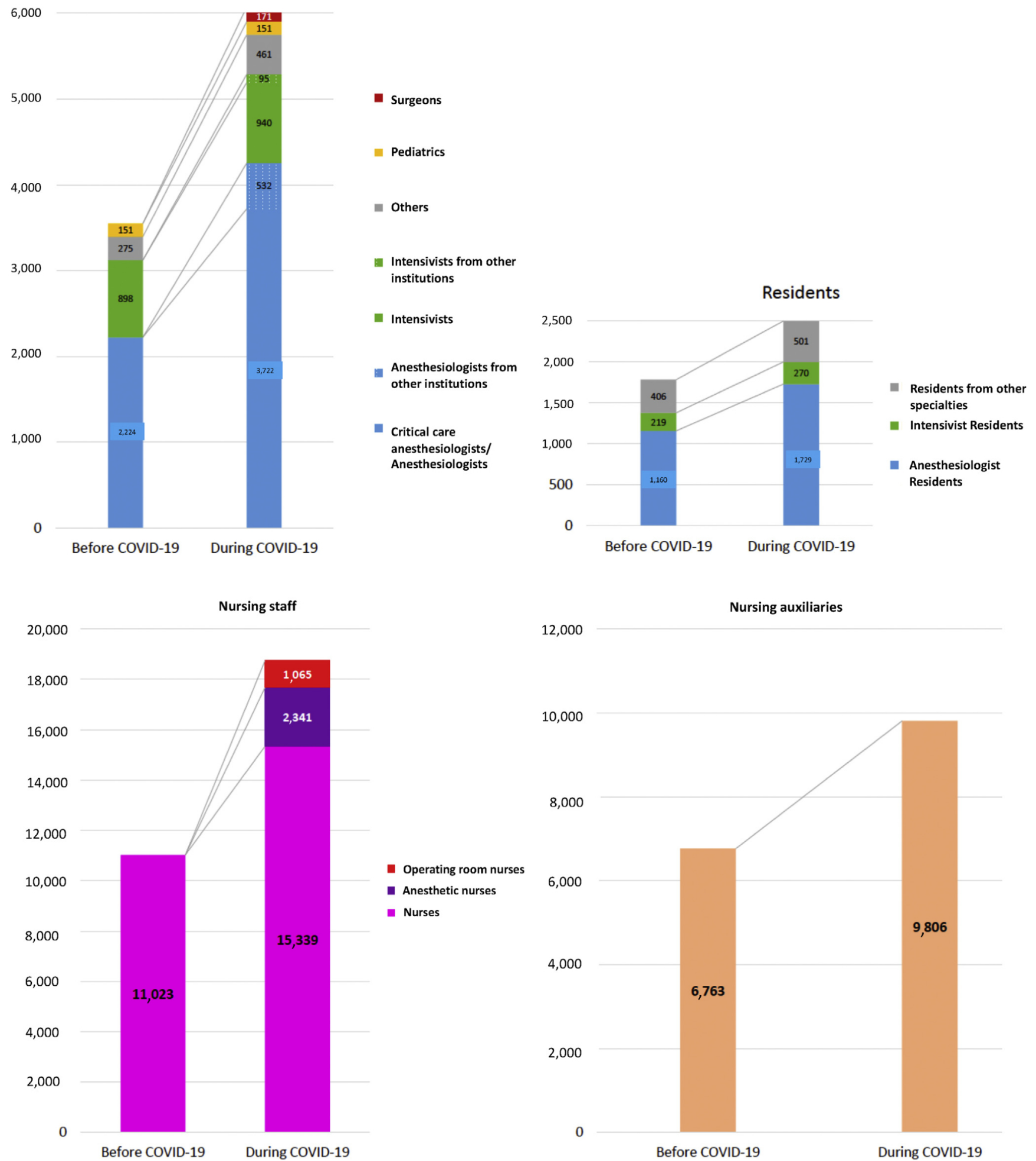

Fig. 3. Increase in caregivers.

At national level, several daily meetings between the director of the regional healthcare agency and the French Minister of Health were held in order to communicate the daily figures on ICU patients and new COVID-19 cases. That way, we could assess the number of available ICU beds in each region and decide on the need to open new ICU beds in a stepwise manner. Evaluation was sometimes facilitated by the use of internet applications showing the availability of beds in real time to all ICU physicians in the same area [6].
When ICUs became overwhelmed in certain regions (such as Grand Est, Bourgogne-Franche-Comté, and Ile-de-France), massive transfers were organised by air and rail [8]. Indeed, 644 patients were admitted to ICUs in other regions or other countries [27].

Key lessons can be drawn from this outbreak on a national scale. ICU bed capacity can be rapidly and dramatically increased in the event of a national pandemic crisis. A 95\% increase in ICU beds was observed even though the number of ACU and PACU beds had 
decreased ( -41 and $-37 \%$, respectively). This organisation model allowed to prevent overwhelming of the 5531 ICU beds initially available before the outbreak.

Collaboration between all specialties involved in the management of the most serious cases (intensivists, critical care anaesthesiologists, anaesthesiologists, emergency physicians) clearly strengthens the capacity to respond to the need to increase ICU capacity. Overlapping skills between different medical specialties was probably a positive element in the response to the outbreak. Also, this rapid adaptation of the healthcare system would not have been possible without a strong collaboration between all administrative and medical staffs at institutional, regional and national levels.

In the event of a similar crisis, a particular concern could arise from the availability of ventilators. Indeed, our study shows that it was more complicated to increase their number than the number of ICU beds. This finding is in line with other shortages reported during the outbreak.

The present study has certain limitations. First, we were unable to contact every unit, but the national response rate $>90 \%$ of ICU beds initially available would probably allow us to draw certain conclusions and lessons for the future. Secondly, this organisation focused on ICU-bed capacity and human resources in terms of caregivers. Unfortunately, this did not prevent certain shortages of anaesthetic supplies and personal protective equipment. Thirdly, such arrangements are probably easier in small countries with high population densities where cities are close to each other $[26,28]$. Indeed, in France, patient transfers could be organised from one region to another or to foreign countries less than $1000 \mathrm{~km}$ away. In bigger countries (USA, Canada, Russia and Australia) a different kind of organisation may be more appropriate. Lastly, the present study did not aim at analysing the impact of such organisation on patient outcome, especially mortality rate. On the $12^{\text {th }}$ of May, a partial evaluation of Santé Publique France agency reported 546 deaths over 2307 ICU admitted patients with a complete follow-up (24\%) between the $16^{\text {th }}$ of March and the $10^{\text {th }}$ of May [29]. Docherty et al. [30] reported 26\% mortality among 20,133 patients with COVID-19 admitted in 208 acute care hospitals in England, Wales and Scotland between the $6^{\text {th }}$ of February and the $19^{\text {th }}$ of April 2020. The mortality rates for patients admitted to ICUs and mechanically ventilated patients were $32 \%$ and $37 \%$, respectively. In Italy, a recent study reported a $26 \%$ ICU mortality rate [31]. The number of deaths reported per million inhabitants is 455 for France, 573 for Italy, 606 for Spain and 632 for the UK [32].

In conclusion, the present study reports on the French healthcare system's response to the COVID-19 outbreak. Using ACU and PACU beds allowed us to double the number of ICU beds available in less than two weeks. Collaboration between intensivists, critical care anaesthesiologists, anaesthesiologists, emergency physicians as well as the mobilisation of nursing staff were primordial in this context.

Conflict of interest

None.

\section{Funding}

Logistical support by Nîmes University Hospital.

\section{Ethical statement}

This retrospective multicentric observational study was approved by the Institutional Review Board of the French Society of Anesthesia and Intensive Care (CERAR\# 00010254-2020-094, $6^{\text {th }}$ of May 2020) and registered on Clinical Trials (NCT04420286).
STROBE recommendations for observational studies were followed.

\section{Acknowledgment}

The authors thank Mrs Teresa Sawyers for her help in checking the English language.

\section{References}

[1] Lu H, Stratton CW, Tang YW. Outbreak of pneumonia of unknown etiology in Wuhan China: hemystery and the miracle [published January 16, 2020]. J Med Virol 2020;92:401-2. http://dx.doi.org/10.1002/imv.25678.

[2] https://www.who.int/docs/default-source/coronaviruse/transcripts/ihremergency-committee-for-pneumonia-due-to-the-novel-coronavirus-2019ncov-press-briefing-transcript-22012020.pdf?sfvrsn=b94d86d9_2.

[3] WHO Writing Group, Bell D, Nicoll A, Fukuda K, Horby P, Monto A, et al. Nonpharmaceutical interventions for pandemic influenza, international measures. Emerg Infect Dis 2006:12:81-7.

[4] https://www.gouvernement.fr/info-coronavirus/carte-et-donnees.

[5] https://www.legifrance.gouv.fr/affichCode.do?idSectionTA= LEGISCTA000006190468\&cidTexte=LEGITEXT000006072665\&dateTexte $=$ 20101014.

[6] Terrasi B, Arnaud E, Guilbart M, Besserve P, Mahjoub Y. French ICUs fight back: an example of regional ICU organisation to tackle the SARS-CoV-2 outbreak. Anaesth Crit Care Pain Med 2020;S2352-5568:30058. http://dx.doi.org 10.1016/j.accpm.2020.03.018.

[7] Déserts MDD, Mathais Q, Luft A, Escarment J, Pasquier P. Conception and deployment of a 30-bed field military intensive care hospital in Eastern France during the 2020 COVID-19 pandemic. Anaesth Crit Care Pain Med 2020;S2352-5568:30075-8. http://dx.doi.org/10.1016/j.accpm.2020.04.008.

[8] Boutonnet M, Turc J, Dupre HL, Paris R, Muller V. "MoRPHEE" fighting COVID19. Anaesth Crit Care Pain Med 2020;S2352-5568. http://dx.doi.org/10.1016 j.accpm.2020.05.002. 30085-0.

[9] Assistance Publique-Hôpitaux de Paris'response to the COVID-19 pandemic Hirsch $m$ and the COVID19 APHP group. Lancet 2020;395(10239). 1760-176.

[10] Fagiuoli S, Lorini FL, Remuzzi G, Covid-19 Bergamo Hospital Crisis Unit. Adaptations and lessons in the Province of Bergamo. $\mathrm{N}$ Engl J Med 2020;382:e71. http://dx.doi.org/10.1056/NEJMc2011599.

[11] Harkouk H, Jacob C, Fletcher C. Urgent development of an anesthesiologybased intensive care unit for critical COVID infected patients. Anaesth Crit Care Pain Med 2020. http://dx.doi.org/10.1016/j.accpm.2020.04.011. S2352 5568: 30078-3.

[12] https://www.gouvernement.fr/info-coronavirus/carte-et-donnees.

[13] https://drees.solidarites-sante.gouv.fr/IMG/pdf/ar_2018.pdf.

[14] Toulouse E, Masseguin C, Lafont B, McGurk G, Harbonn A, et al. French legal approach to clinical research. Anaesth Crit Care Pain Med 2018;201(37): 607-14.

[15] von Elm E, Altman DG, Egger M, Pocock S], Gøtzsche PC, Vandenbroucke JP, STROBE Initiative. The strengthening the reporting of observational studies in epidemiology (STROBE) statement: guidelines for reporting observational studies. Ann Int Med 2007:147:573-7.

[16] Leone M, Constantin JM, Dahyot-Fizelier C, Durachet-Gout C, Joannes-Boyau O, et al. French intensive care unit organisation. Anaesth Crit Care Pain Med 2018;37:625-7.

[17] Harris A, Taylor R, Minor BL, Elliot V, Fernandez M, et al. REDCap Consortium. The REDCap consortium: building an international community of software partners. J Biomed Inform 2019;95103208. http://dx.doi.org/10.1016/ j.jbi.2019.103208.

[18] Cushman JG, Pachter HL, Beaton HL. Two New York city hospitals' surgical response to the September 11, 2001, terrorist attack in New York City. ] Trauma 2003;54:147-54.

[19] Gutierrez de Ceballos JP, Turégano-Fuentes F, Pérez-Díaz D, Martin-Llorente C, Guerrero-Sanz JE. March 2004: the terrorist bomb explosions in Madrid, Spain - an analysis of the logistics, injuries sustained and clinical management of casualties treated at the closest hospital. Crit Care 2005;9:104-11.

[20] Aylwin CJ, König TC, Brennan NW, Shirley PJ, Davies G, Walsh MS, et al. Reduction in critical mortality in urban mass casualty incidents: analysis of triage, surge, and resource use after the London bombings on July 7, 2005 . Lancet 2006;368:2219-25.

[21] Hirsh M, Carli P, Nizard R, Riou B, Baroudjian B, Baubet T, et al. The medica response to multisite terrorist attacks in Paris. Lancet $2015 \cdot 386: 2535-8$.

[22] Orban JC, Quintard, Ichai C. ICU specialists facing terrorist attack: the nice experience. Intensive Care Med 2017;43:683-5. 
[23] Peters AW, Chawla KS, Turnbull ZA. Transforming ORs inti ICUs. N Engl J Med 2020;382:e52.

[24] Yager PH, Whalen KA, Cummings BM. Repurposing a pediatric ICU for adults. N Engl J Med 2020;382:e80.

[25] Einav S, Hick JL, Hanfling D, Erstad BL, Toner ES, Branson RD, et al. Surge capacity logistics: care of the critically ill and injured during pandemics and disasters: CHEST consensus statement. Chest 2014;146(4 Suppl):e17S-43S.

[26] Hick JL, Biddinger PD. Novel coronavirus and old lessons - preparing the health system for the pandemic. N Engl J Med 2020;382:e55.

[27] https://www.gouvernement.fr/info-coronavirus/carte-et-donnees.

[28] Kandel N, Chungong S, Omaar A, Xing J. Health security capacities in the context of COVID-19 outbreak: an analysis of International Health Regulations annual report data from 182 countries. Lancet 2020;395:1047-53.
[29] https://www.santepubliquefrance.fr/maladies-et-traumatismes/ maladies-et-infections-respiratoires/infection-a-coronavirus/documents/ bulletin-national/covid-19-point-epidemiologique-du-14-mai-2020.

[30] Docherty AB, Harrison EM, Green CA, Hardwisk HE, Pius R, Norman L, et al. Features of 20133 UK patients in hospital with covid-19 using the ISARIC WHO clinical characterisation protocol: prospective observational cohort study. Br Med J 2020;369:m1985. http://dx.doi.org/10.1136/bmj.m1985. 10.1136/bmj.m1985.

[31] Grasselli G, Zangrillo A, Zanella A, Antonelli M, Cabrini L, Castelli A, et al Baseline characteristics and outcomes of 1591 patients infected with SARSCoV-2 admitted to ICUs of the Lombardy Region, Italy. JAMA 2020;323:157481. http://dx.doi.org/10.1001/jama.2020.5394.

[32] https://www.worldometers.info/coronavirus/. 